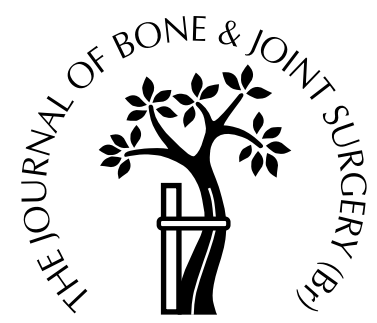

\title{
Osteochondroma with compression of the spinal cord
}

\author{
A REPORT OF TWO CASES \\ S. Govender, A. H. Parbhoo \\ From the University of Natal, Durban, South Africa
}

$\mathbf{W}$ Te report two cases of vertebral osteochondroma. In one patient a solitary cervical lesion presented as entrapment neuropathy of the ulnar nerve and in the other as a thoracic tumour associated with hereditary multiple exostoses producing paraplegia. We highlight the importance of an adequate preoperative evaluation in such patients.

J Bone Joint Surg [Br] 1999;81-B:667-9.

Received 30 June 1998; Accepted after revision 7 December 1998

Benign cartilaginous tumours are commonly found in the appendicular skeleton but rarely in the spine. ${ }^{1}$ Osteochondromas usually arise in the spine from the neural arch and compression of the spinal cord is seen more often in hereditary multiple exostoses than in a solitary lesion. ${ }^{2,3}$

\section{Case Reports}

Case 1. A 33-year-old man presented with a nine-month history of neck pain and loss of grip strength of the left hand. Ten years previously a mass had been excised from the posterior area of his neck (Fig. 1). Examination showed tenderness over the left paraspinal area and there was clawing of the left hand. The grip was of power 3 on the MRC grading. He had no sensory impairment in the left arm. Radiographs showed a bony mass; CT and MRI revealed compression of both the cord and the C8/T1 nerve roots (Fig. 2). At operation a well-encapsulated mass was found arising from the posterior elements of C7 and T1 and causing compression of the $\mathrm{C} 8 / \mathrm{T} 1$ nerve roots. It was removed and the nerve roots decompressed. Histological examination confirmed that it was a benign osteochondroma. Neck pain improved after operation but there was no significant recovery of grip. After two years MRI showed no evidence of recurrence.

S. Govender, FRCS, Professor

A. H. Parbhoo, FCS (Ortho) SA, Consultant Orthopaedic Surgeon

Department of Orthopaedic Surgery, University of Natal, Private Bag 7, Congella, 4013 Durban, Republic of South Africa.

Correspondence should be sent to Professor S. Govender.

(C)1999 British Editorial Society of Bone and Joint Surgery 0301-620X/99/49248\$2.00

VOL. 81-B, No. 4, JULY 1999
Case 2. A 14-year-old girl was referred with a four-month history of weakness of both lower limbs and a one-month history of urinary incontinence. She had had antituberculous therapy for two months. There was left-sided tenderness of the lower thoracic spine but no deformity. She had multiple asymptomatic exostoses. The lower limbs were spastic but with intact sensation. Radiographs revealed an exostosis involving the neural arch of D8 (Fig. 3). CT and MRI showed compression of the cord (Fig. 4). Posterior decompression of D8 was performed and a large cartilaginous mass removed. Histological examination confirmed it to be an exostosis. She made a complete neurological recovery over a period of three months.

\section{Discussion}

Between $1 \%$ and $4 \%$ of solitary osteochondromas arise in the spine and $7 \%$ to $9 \%$ of patients with hereditary multiple exostoses develop a spinal lesion. ${ }^{4-6}$ Solomon $^{5}$ reported an incidence of $9 \%$ of spinal osteochondromas in a series of 52 patients with hereditary multiple exostoses. All were asymptomatic. Compression of the spinal cord is an uncommon manifestation of osteochondroma. ${ }^{2,3,6,7}$ The neurological deficit is invariably the result of compression caused by an expanding lesion arising from the posterior elements. Less often, lesions causing neural compression originate from the vertebral bodies or heads of the rib. Anterior spinal osteochondromas in the neck can present as a pharyngeal mass with hoarseness or dysphagia.

A search of the literature ${ }^{1,2,6-15}$ has shown that 117 cases of symptomatic spinal osteochondroma were reported between 1843 and 1997 either as solitary lesions or multiple exostoses (Table I). Pain was the commonest symptom in both groups but a palpable mass was found more often with solitary lesions. Both solitary and multiple osteochondromas affect males more frequently than females and patients with multiple exostoses presenting with a spinal lesion are usually younger (mean age 20 years) than those with a solitary osteochondroma (mean age 30 years). Myelopathy is predominantly seen with both multiple and solitary osteochondromas but is more common in the former. $^{2,3,6,11-13}$ There was delay in presentation in both of our patients and delays of up to ten years have previously been reported. ${ }^{13}$ In our first patient, recurrence was attributed to 


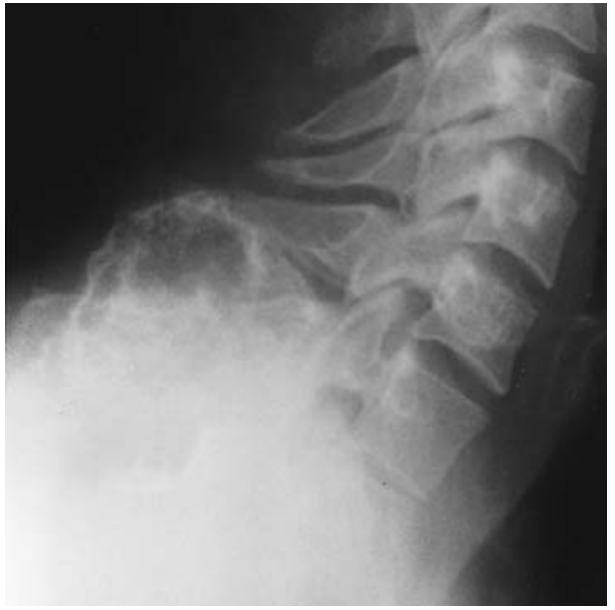

Fig. 1a

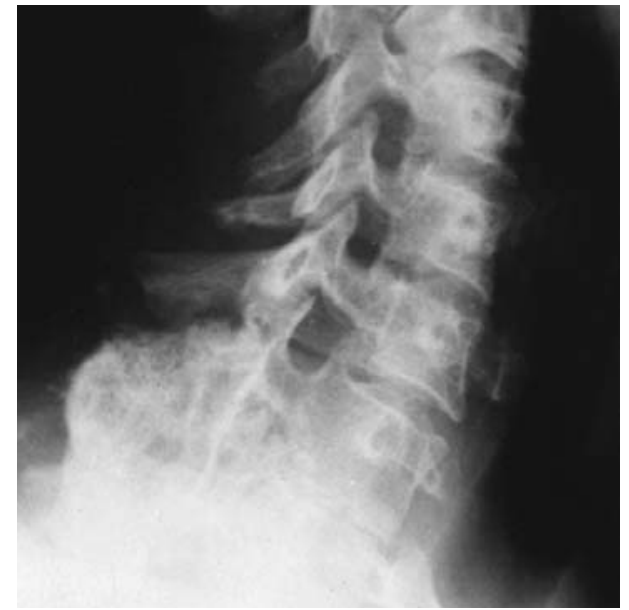

Fig. 1b

Case 1. Radiographs showing a) a solitary osteochondroma at the cervicodorsal junction and b) recurrence ten years after excision.

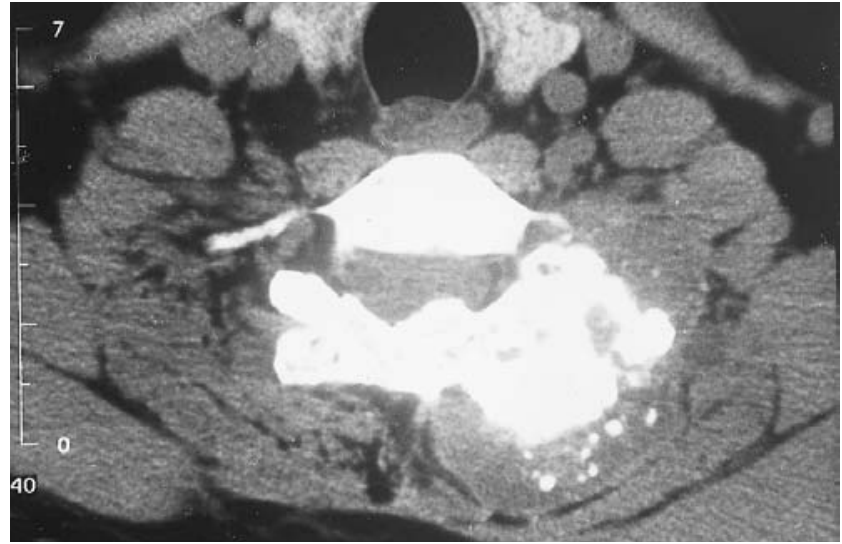

Fig. 2a

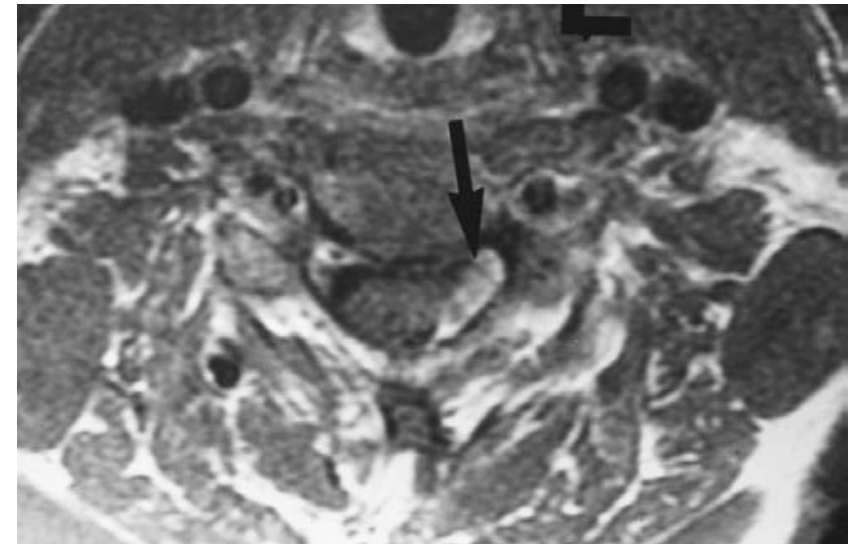

Fig. $2 b$

Case 1. Axial CT showing the extent of involvement of the posterior element (a) and MRI showing compression of the cord and root on the left side (arrow) (b).

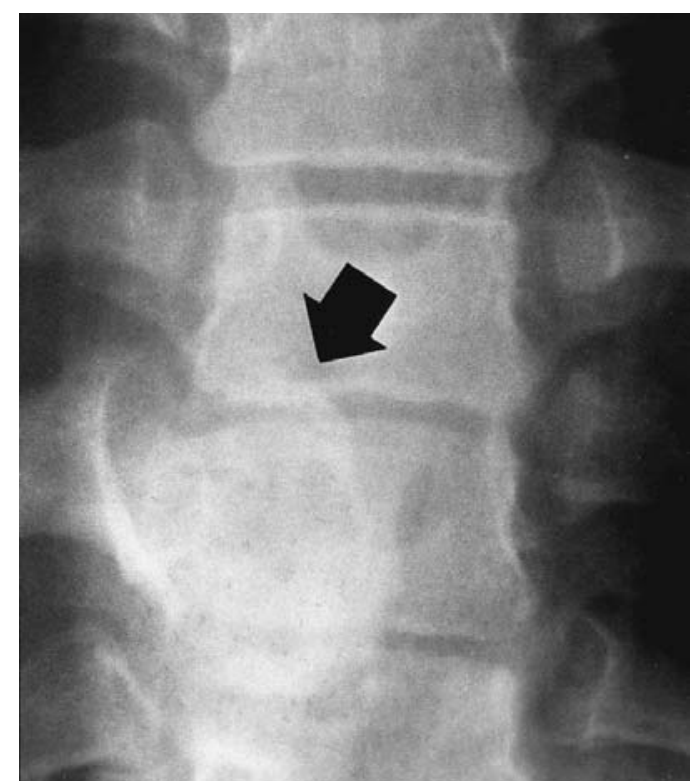

Fig. 3

Case 2. Radiographs showing a bony lesion involving the posterior elements of D8 (arrow). 


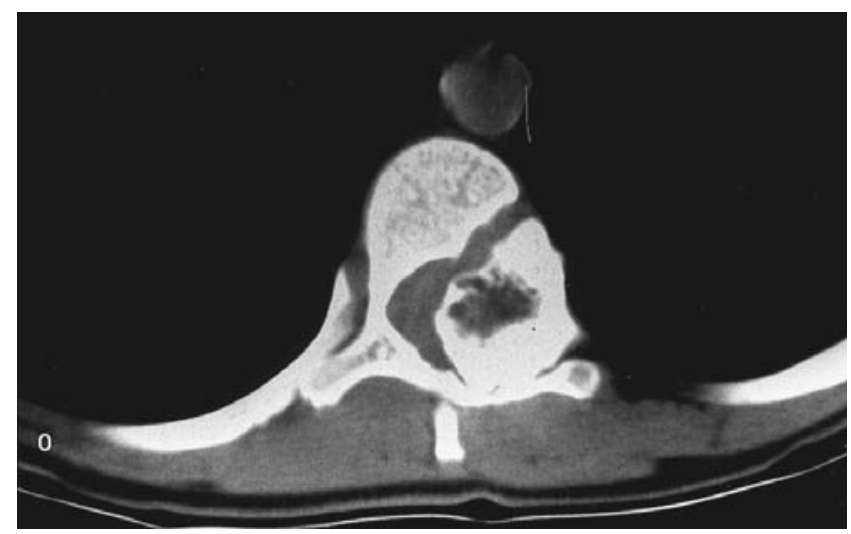

Fig. 4a

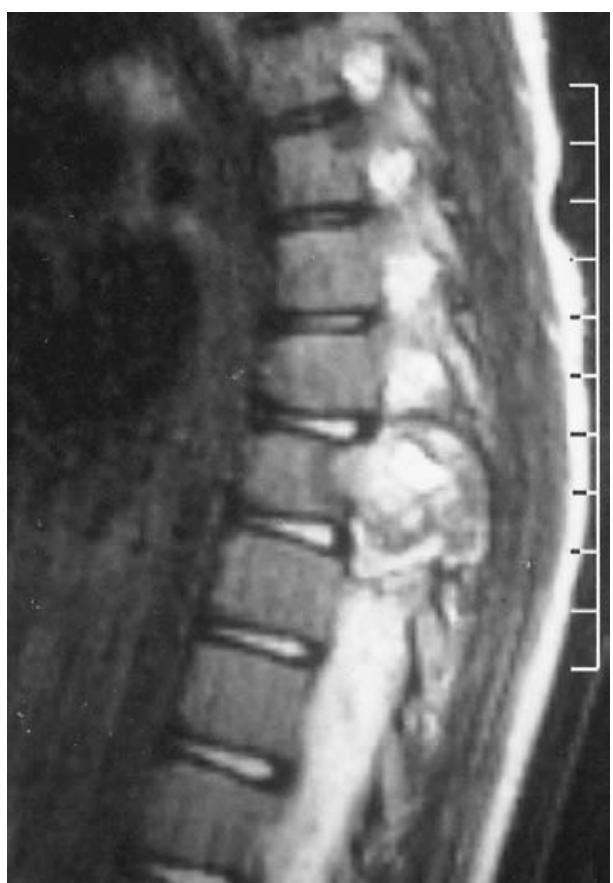

Fig. 4b Case 2. CT showing compression of the cord (a) and MRI sagittal
reconstruction showing the cartilaginous component of the exostosis (b).

5. Solomon L. Hereditary multiple exostosis. J Bone Joint Surg [Br] 1963;45-B:292-304.

6. Carmel PW, Cramer FJ. Cervical cord compression due to exostosis in a patient with hereditary multiple exostoses: case report. $\mathrm{J} \mathrm{Neu}$ rosurg 1968;28:500-3.

7. Albrecht S, Crutchfield JS, Se Gall GK. On spinal osteochondromas. J Neurosurg 1992;77:247-52.

8. Ilgenfritz HC. Vertebral osteochondroma. Am Surg 1951;17:917-22.

9. Morard M, de Preux J. Solitary osteochondroma presenting as a neck mass with spinal cord compression syndrome. Surg Neurol 1992;37: 402-5.

10. Van der Sluis R, Gurr K, Joseph MG. Osteochondroma of the lumbar spine: an unusual case of sciatica. Spine 1992;17:1519-21.

11. Arasil E, Erdem A, Yuceer N. Osteochondroma of the upper cervical spine: a case report. Spine 1996;21:516-8.

12. Okuyama K, Chiba M, Okada K, Sato K, Hoshi N. Huge solitary osteochondroma at T11 level causing myelopathy: case report. Spinal Cord 1997;35:773-6.

13. Cooke RS, Cumming WJ, Cowie RA. Osteochondroma of the cervical spine: case report and review of the literature. $\mathrm{Br} J$ Neurosurg 1994;8:359-63.

14. Calhoun JM, Chadduck WM, Smith JL. Single cervical exostosis: report of a case and review of the literature. Surg Neurol 1992; 37:26-9.

15. Palmer FJ, Blum PW. Osteochondroma with spinal cord compression: report of three cases. J Neurosurg 1980;52:842-5. 